\title{
BIMBINGAN DAN PELATIHAN SENI MERAJUT BAGI IBU-IBU ANGGOTA KOMITE SEKOLAH SDN LOWOKWARU 3 MALANG
}

\author{
Ellyn Eka Wahyu ${ }^{1)}$, Pudji Herijanto ${ }^{2)}$, Siti Nurbaya ${ }^{3)}$, Halid Hasan ${ }^{4)}$, Bambang Suryanto ${ }^{5)}$ \\ 1,2,3,4,5 Jurusan Administrasi Niaga Politeknik Negeri Malang \\ Email: ekaellyn@gmail.com
}

\begin{abstract}
Abstrak - Program Pengabdian ini merupakan kegiatan bimbingan dan pelatihan seni merajut bagi anggota Komite Sekolah SDN Lowokwaru 3 Malang. Kegiatan ini bertujuan agar anggota komite sekolah memiliki bekal ilmu seni kriya yang diharapkan agar dapat penghasilan tambahan melalui seni kriya mandiri. Metode Pengabdian dilaksanakan dengan mendatangkan instruktur rajut Kota Malang dan alih pengetahuan dilaksanakan dengan cara cara diskusi dan tanya jawab beserta praktikum. Hasil dari kegiatan pengabdian ini berupa bros rajut. Diharapkan bagi ibu-ibu anggota komite sekolah SDN Lowokwaru 3 Malang dapat mengaplikasikan seni rajut sebagai sarana untuk memperoleh penghasilan tambahan melalui seni kriya mandiri.
\end{abstract}

Kata kunci: Bimbingan, Seni Merajut, Ibu-Ibu Komite Sekolah.

\section{PENDAHULUAN}

\subsection{Latar Belakang}

Pendidikan merupakan kebutuhan manusia yang mendapat perhatian besar di masyarakat, karena pendidikan dapat menjadikan manusia berkembang menjadi individu yang memiliki pengetahuan, sikap dan ketrampilan yang dapat menunjang kehidupan dalam bermasyarakat, serta mampu menghadapi perkembangan zaman.

Pendidikan merupakan modal penting di dalam kemajuan suatu bangsa, oleh karena itu pendidikan menjadi perhatian utama dalam kehidupan masyarakat mulai dari masyarakat lingkungan kecil yaitu keluarga sampai lingkungan besar yaitu bangsa, realisasi dari tujuan dan fungsi pendidikan nasional di atas, ditempuh dan dilaksanakan melalui pendidikan formal, informal dan non-formal sebagaimana tercantum dalam Undang- Undang RI No. 20 Tahun 2003 tentang Sistem Pendidikan Nasional BAB IV pasal 13 ayat 1 (2012:10).

Fungsi dari pendidikan non-formal yaitu sebagai pengganti, penambah, dan atau ingin melengkapi pendidikan formal, dalam memenuhi kebutuhan dengan berbagai ketrampilan dan penguasaan pengetahuan fungsional serta pengembangan sikap dan kepribadian yang profesional.

Ibu-ibu Anggota Komite Sekolah SDN Lowokwaru 3 Malang, dalam kegiatan sehari-harinya selain mengurus rumah tangga tidak memiliki pekerjaan tetap dan penghasilan tetap sehingga untuk mengisi waktu luangnya terlihat belum maksimal oleh sebab itu diperlukan suatu kegiatan yang lebih bermanfaat (pendidikan non formal yaitu ketrampilan) berupa bimbingan dan pelatihan untuk memaksimalkan waktu luang tersebut agar dapat meghasilkan sesuatu yang bernilai guna dan kedepannya dapat digunakan sebagai bekal ilmu untuk menjadi seorang entrepreneur melalui usaha kriya mandiri.

Permasalahan yang muncul saat ini (terutama) adalah makin tingginya kebutuhan ekonomi dalam keluarga yang harus dipenuhi sehingga diperlukan suatu cara untuk menambah penghasilan dalam keluarga. Salah satu bimbingan dan pelatihan yang dapat memberikan bekal pengetahuan dan ketrampilan bagi ibu-ibu dan remaja putri dalam kesiapan usaha kriya mandiri yaitu bimbingan dan pelatihan seni merajut.

\section{TINJAUAN PUSTAKA}

\subsection{Seni}

Seni pada mulanya adalah suatu proses dari manusia, dan oleh karena itu merupakan sinonim dari ilmu. Menurut Alexander Baum Garton, seni adalah keindahan dan seni adalah tujuan yang positif menjadikan penikmat merasa dalam kebahagiaan. Sejalan dengan teori tersebut, Ki Hajar Dewantara mengemukakan bahwa seni merupakan hasil keindahan sehingga dapat menggerakkan perasaan indah orang yang melihatnya, oleh karena itu perbuatan manusia yang dapat mempengaruhi dapat menimbulkan perasaan indah itu seni.

\subsection{Rajut}

Menurut Kamus Kamus Besar Bahasa Indonesia, rajut adalah (1) jaring-jaring ; jala-jala. (2) Siratan benang yang berupa jaring untuk pundi-pundi, penutup sanggul, dan sebagainya. (3) Pundi-pundi (pura) yang dibuat dari siratan benang, rami, dan sebagainya. (4) Bahan pakaian yang disirat dengan tangan atau mesin rajut. Menurut Wikipedia, merajut atau rajut (bahasa Inggris : knitting) adalah metode membuat kain, pakaian atau perlengkapan busana dari benang rajut. Berbeda dari menenun yang menyilangkan dua jajaran benang yang saling tegak lurus, merajut hanya menggunakan sehelai benang. 


\subsection{Macam-Macam Pola Rajut Dasar}

Agar bisa membuat bermacam-macam rajutan indah, juga harus belajar membuat bermacam-macam pola rajut standar. Akan tetapi, walaupun standar, kumpulan pola rajut ini juga cantik dan pastinya akan sangat indah jika dijadikan berbagai macam barang buatan sendiri. Berikut ini adalah bermacam-macam pola rajut dasar yang sebaiknya dikuasai :

\section{a. Pola Stockinette}

Pola ini membentuk garis-garis memanjang yang sangat khas, yang biasanya terdiri dari tiga warna berselang seling. Motif ini sering dipakai untuk membuat benda-benda macam taplak, celemek bayi, lap dan syal, pokoknya benda-benda yang bentuknya biasanya terdiri dari garis-garis lurus macam persegi atau persegi panjang. Keunikan dari rajutan ini adalah bisa membuat bentuk yang pinggirannya menggulung atau lurus. Pola rajut Stockinette dapat dilihat pada Gambar 1. dibawah ini :

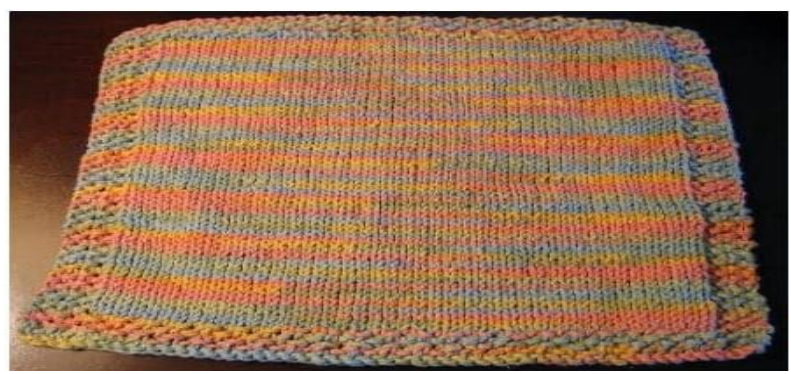

Gambar 1. Pola Rajut Stockinette

\section{b. Pola Garter Stitch}

Pola rajut simpel ini paling sering disarankan untuk dicoba para pemula yang baru belajar membuat pola. Pasalnya, proses pembuatan pola rajut ini memang tidak terlalu rumit; cukup dengan merajut semua barisnya dan bisa dengan hanya menggunakan satu jenis dan warna benang. Hasil akhir dari pola rajaut ini unik dan cantik, dengan aksen tonjolan besar-besar. Pola rajut Garter Stitch dapat dilihat pada Gambar 2. dibawah ini :

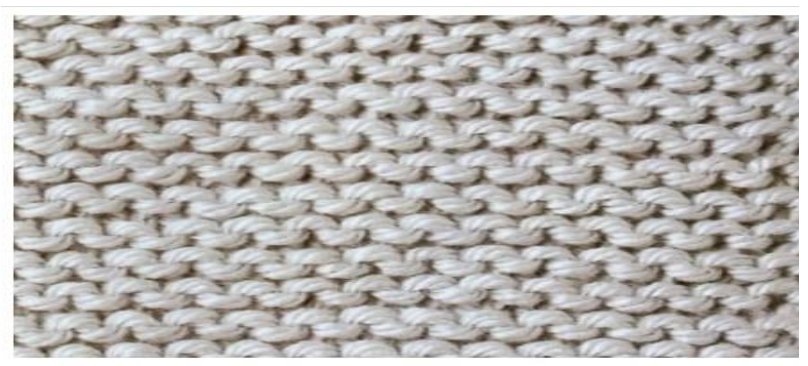

Gambar 2. Pola Rajut Garter Stitch

\section{c. Pola Seed Stitch}

Seperti namanya, pola rajut seed stitch ini berbentuk menonjol nampak mirip biji kecil-kecil. Ketika merajut pola ini, sisi depan dan belakangnya nampak sama. Jadi pola ini cocok untuk merajut benda yang bagian depan dan belakangnya keliatan seperti syal. Pola rajut Seed Stitch dapat dilihat pada Gambar 3. dibawah ini :

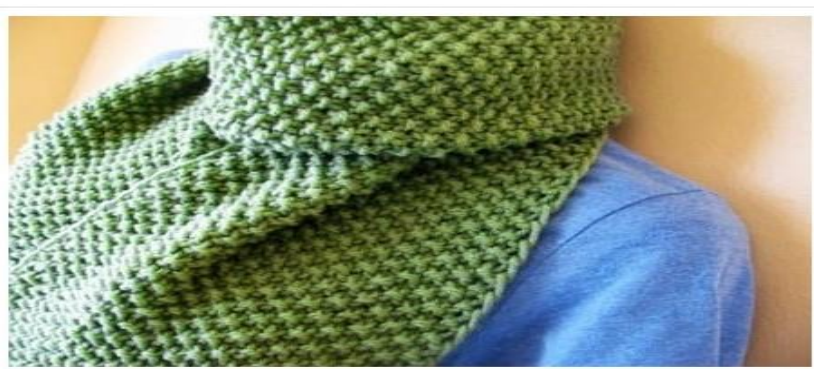

Gambar 3. Pola Rajut Seed Stitch

Pola Checkerboard

Pola rajut ini mulai agak rumit karena mengkombinasikan dua warna benang untuk menghasilkan bentuk kotak-kotak mirip papan catur. Jika hanya menggunakan satu benang, teknik merajut yang diterapkan untuk pola ini tetap akan menghasilkan pola kotak-kotak. Pola rajut Checkerboard dapat dilihat pada Gambar 4. dibawah ini :

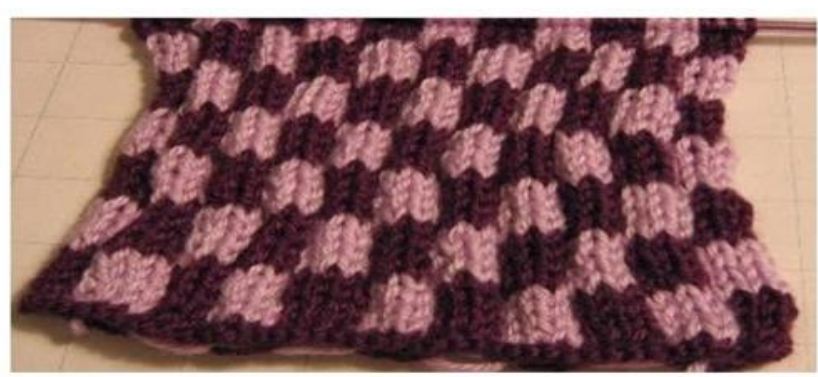

Gambar 4. Pola Rajut Checkerboard

\section{d. Pola Sarang Lebah (Honeycomb)}

Pola rajut ini kelihatan rumit karena membentuk pola sarang lebah yang cantik, namun sebenarnya termasuk rajutan dasar. Pola ini sangat cocok untuk membuat baju hangat atau sweater, sarung tangan dan selimut.

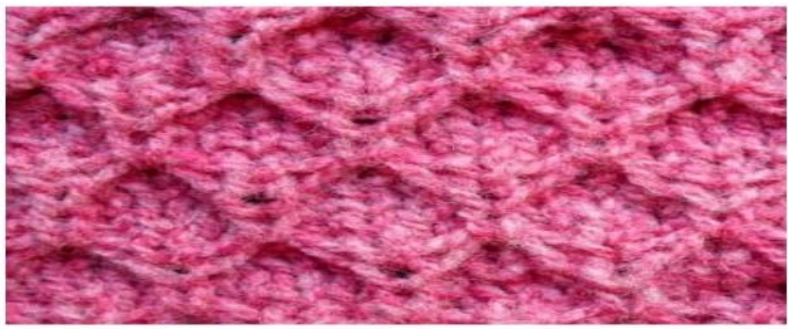

Gambar 5. Pola Rajut Honeycomb

\section{METODE ALIH PENGETAHUAN}

Alih pengetahuan diberikan kepada 20 orang peserta pelatihan dengan metode penyampaian materi 
yang sesuai dengan disertai contoh-contoh dalam bentuk sketsa gambar mengenai pola- pola rajut. Kemudian metode tersebut disertai dengan diskusi dan tanya jawab kepada instruktur rajut agar ilmu yang disampaikan dapat diserap dengan baik.

\section{HASIL DAN PEMBAHASAN}

\subsection{Proses Pelaksanaan Pengabdian Kepada Masyarakat (PKM)}

Pengabdian Kepada Masyarakat ini memiliki tujuan dan sasaran yang diharapkan dapat memberi manfaat bagi khalayak yang menjadi sasaran. Tujuan dari Pengabdian Kepada Masyarakat ini adalah untuk memberikan solusi alternatif bagi para ibu-ibu rumah tangga yang belum memiliki penghasilan tetap agar memiliki keterampilan yang memiliki nilai ekonomi yang tinggi. Keterampilan tersebut adalah keterampilan merajut, khususnya membuat produk bros rajut. Kegiatan ini dilakukan dengan rincian sebagai berikut:

- Mengumpulkan bahan-bahan yang digunakan untuk membuat bros rajut seperti benang rajut aneka warna, hakpen, gunting, tatakan rajut, aksesoris tambahan seperti kancing dan yang terakhir adalah jarum sulam.

- Mengumpulkan peserta pelatihan membuat bros rajut di gedung pertemuan yang telah ditentukan.

- Memberikan sedikit materi tentang prospek usaha rajut yang tidak memerlukan banyak biaya dan bernilai tinggi dikarenakan produk handmade yang memiliki ciri khas yang berbeda antara peserta 1 dengan peserta yang lain.

- Kemudian setelah dilakukan presentasi mengenai prospek usaha rajut, maka kegiatan dilanjutkan dengan melakukan kegiatan pembuatan bros rajut yang didampingi oleh praktisi rajut Kota Malang.

Sebelum melakukan proses rajut, peserta perlu memperhatikan istilah-istilah yang terdapat dalam kegiatan merajut supaya dapat dengan mudah mengerti kegiatan merajut. Istilah tersebut antara lain:

- ch (chain atau tusuk rantai)

- $\quad$ sc (single crochet atau tusuk tunggal)

- popdc (tusuk popcorn)

- bpdc (back post double crochet)

- fpdc (front post double crochet)

- $\quad$ sl st (slip stitch atau tusuk selip atau sisip)

- blsc (back loop single crochet)

- hdc (half double crochet)

- dc (double crochet atau tusuk ganda)

- $\quad \operatorname{tr}$ (triple crochet atau tusuk tiga)

Setelah mengetahui istilah-istilah yang sering digunakan dalam merajut, peserta pelatihan juga perlu mengetahui bahan dan alat apa saja dalam membuat rajutan bros, yang dapat dilihat pada Gambar 6. dan Gambar 7. antara lain:

1. Benang Katun,

2. Manik Mutiara untuk hiasan, dan

3. Jarum Hakken nomor 3.

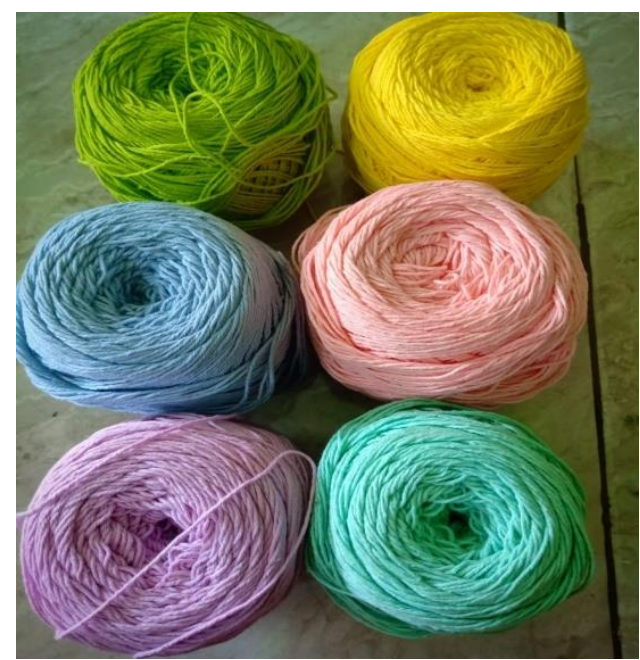

Gambar 6. Benang Katun

Sumber: Data Diolah, 2019

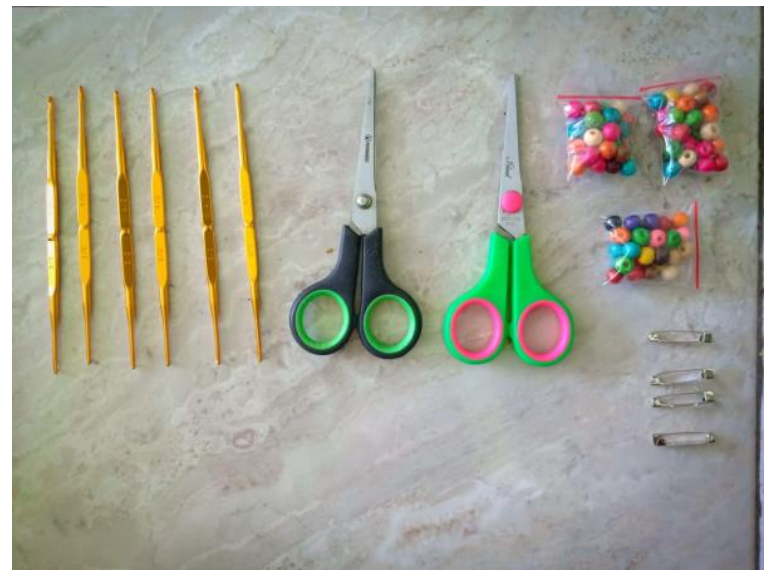

Gambar 7. Jarum Hakpen, Gunting, dan Manik-Manik Sumber: Data Diolah, 2019

Setelah mengetahui istilah-istilah dasar yang berkaitan dengan kegiatan merajut, maka course pertama yang harus dilakukan adalah Latihan Membuat Simpul Dasar / Tusuk Rantai $(\mathrm{CH})$. Berikut ini langkah-langkah dalam membuat rajutan tusuk rantai, dan dapat diperjelas pada Gambar 8. dan Gambar 9. :

- Peserta memegang benang di tangan kiri dan selipkan ujung benang dari belakang kelingking melewati jari manis dan tengah. Kaitkan ke telunjuk.

- Kemudian Jarum dipegang dengan menggunakan tangan kanan dan kepala kait dihadapkan ke arah peserta. 


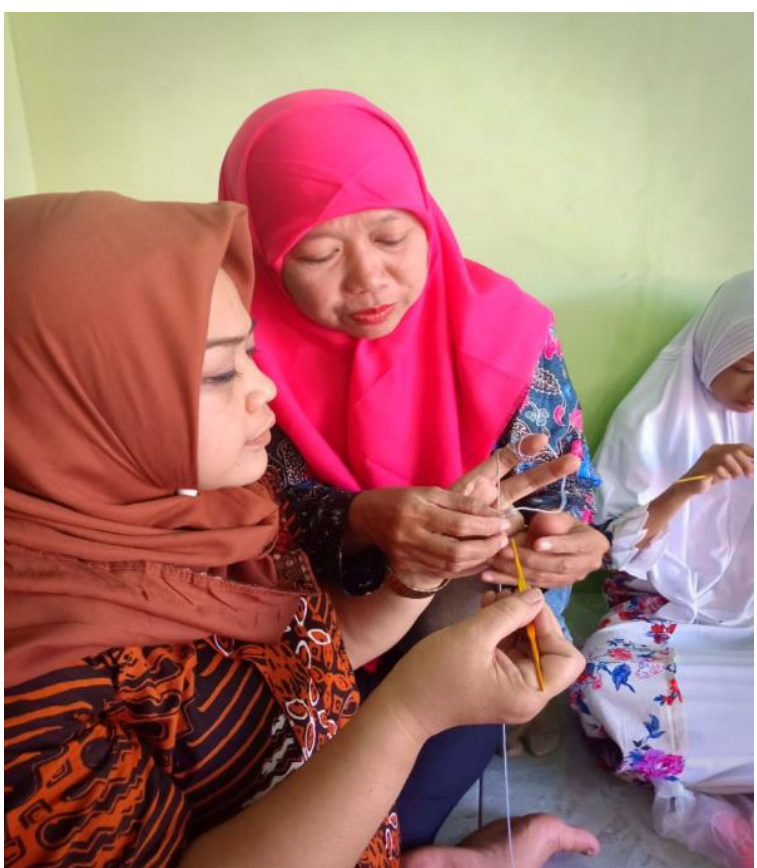

Gambar 8. Posisi Benang dan Jarum dalam membuat Tusuk Rantai Sumber: Data Diolah, 2019

- Selanjutnya, Ibu jari dan jari tengah menjepit jarum, seperti saat kita sedang memegang pulpen.

- Buat chain (ch) atau tusuk rantai yang panjang dan sama ukurannya. Indikasi keberhasilan dalam membuat tusuk rantai yang bagus ialah tusuk rantai yang ukuran dan panjangnya sama dan dapat dimasuki kepala jarum kait.

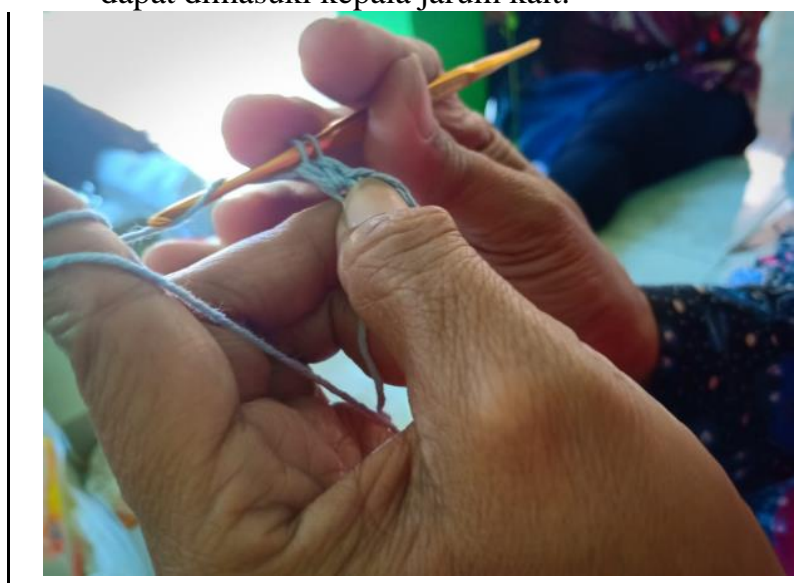

Gambar 9. Proses Pembuatan Pola Tusuk Rantai Sumber: Data Diolah, 2019

Hasil latihan pola tusuk rantai ini dikatakan berhasil apabila peserta mampu membuat pola ini secara berulang dengan tingkat konsistensi yang sama seperti pada Gambar 10. dan Gambar 11. dan dibawah ini:

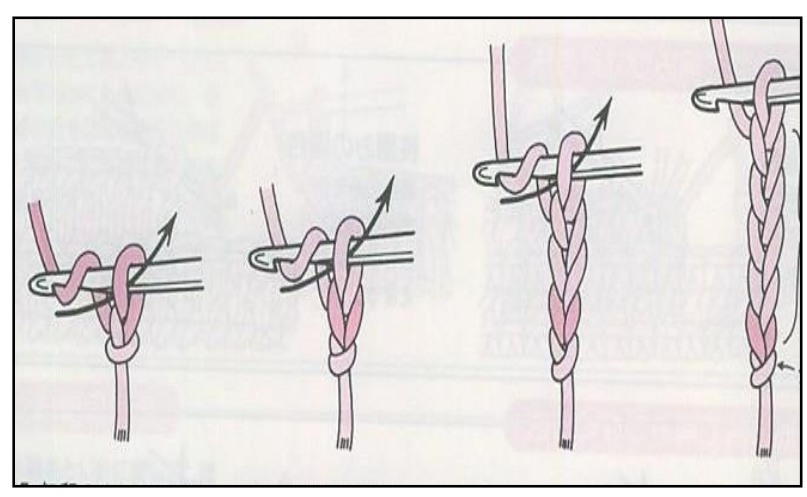

Gambar 10. Pola Tusuk Rantai

Sumber: www.abiummi.com/ diakses pada Agustus 2019

Setelah selesai membuat tusuk rantai dengan ukuran dan panjangnya sama, selanjutnya peserta dapat mematikan (menutup) rajutan. Kemudian, peserta dapat menarik benang sepanjang $1,5 \mathrm{~cm}$ serta gunting, tarik, dan kencangkan ikatan pada benang tersebut. Untuk mendapatkan hasil yang lebih baik, dapat diulangi beberapa kali hingga lancar.

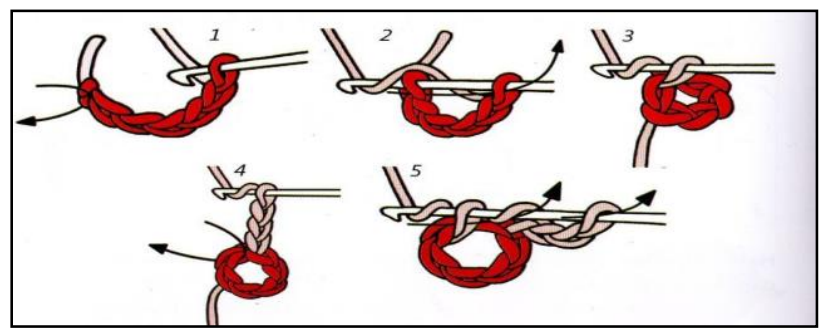

Gambar 11. Cara Mematikan Pola Rajut

Sumber: www.abiummi.com/ diakses pada Agustus 2019

Setelah peserta mampu memahami teknik dasar membuat pola tusuk rantai, selanjutnya peserta dapat melaksanakan course yang kedua yakni Latihan Membuat Single Crochet atau rajut pola tusuk tunggal. Langkah-langkah dalam membuat pola tusuk tunggal antara lain:

Buat tusuk rantai sebanyak 30 buah. Lalu, tambahkan 2 ch (perlu diingat bahwa $1 \mathrm{sc}=2 \mathrm{ch}$ ). Tusuk jarum ke dalam tusuk rantai keempat (hitungan dimulai dari jarum). Kaitkan dan tarik benang melalui sela tusuk rantai sehingga pada jarum terdapat dua lilitan. Kemudian, kait benang sekali lagi dan tarik sehingga pada jarum hanya tersisa satu lilitan benang. Tusukkan jarum pada tusuk rantai berikutnya, kait, dan lakukan seperti tahap sebelumnya. Buatlah tusuk tunggal di sepanjang tusuk rantai yang sudah dibuat. Untuk lebih jelasnya, perhatikan Gambar 12. di bawah ini: 


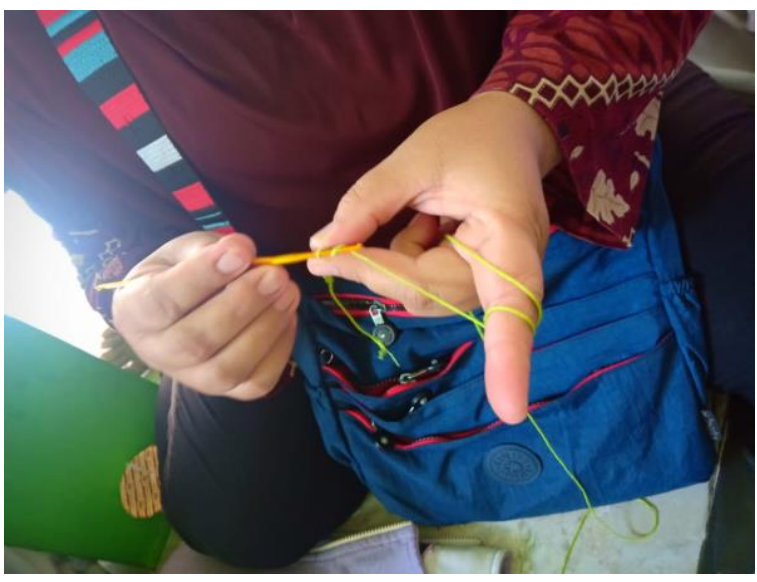

Gambar 12. Cara Membuat Pola Rajut Tusuk Tunggal Sumber: Data diolah 2019

Setelah peserta menguasai teknik rajut tusuk tunggal, maka peserta pelatihan dapat melaksanakan materi bimbingan selanjutnya yakni Teknik Rajut Double Crochet atau Teknik Tusuk Ganda dengan langkah-langkah sebagai berikut:

- Buat tusuk rantai sebagai dasarnya.

- Tambahkan tiga tusuk rantai lagi.

- Kaitkan benang dan masukkan melalui lubang keempat. Kait benang lagi dan tarik melalui dua lubang.

- Kait benang sekali lagi dan tarik melalui dua lubang yang terakhir. Untuk lebih jelasnya, perhatikan Gambar 13. di bawah ini :

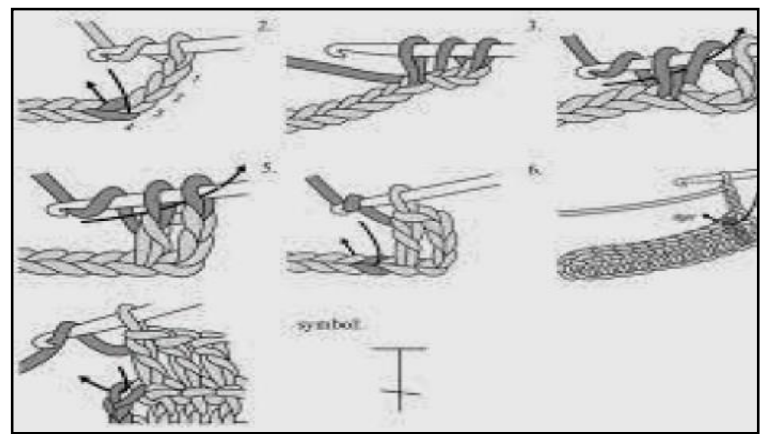

Gambar 13. Cara Membuat Pola Rajut Tusuk Ganda Sumber: www.abiummi.com/ diakses pada Agustus 2019

Kemudian setelah peserta menguasai teknik rajut tusuk ganda, maka peserta pelatihan dapat melaksanakan materi bimbingan selanjutnya yakni Teknik Rajut Tiga Tusuk Rantai dengan langkahlangkah sebagai berikut:

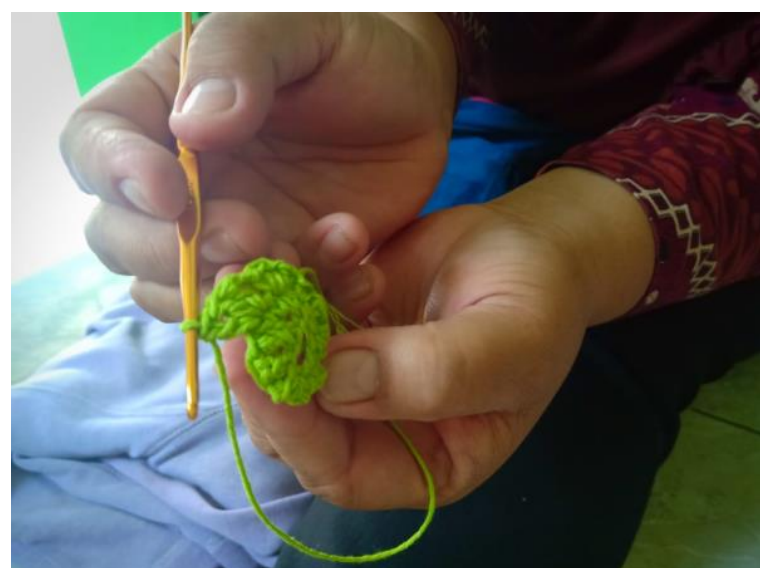

Gambar 14. Cara Membuat Pola Rajut Tusuk Tiga Sumber: Data Diolah, 2019

Setelah berhasil membuat keempat simpul di atas (tusuk rantai, tusuk tunggal, tusuk ganda, dan tusuk tiga), maka peserta pelatihan dapat melanjutkan ke tahap selanjutnya yakni membuat rajutan bros bunga. Bunga yang dibuat di sini adalah bunga ruffle. Proses pembuatan rajutan bros bunga ini dibagi menjadi dua bagian, yaitu bagian pertama sebagai dasar dan bagian kedua sebagai bagian atas. Langkah pertama yakni sebagai berikut:

\section{A. Bagian Pertama}

- Buatlah tusuk rantai sebanyak 6 buah. Kemudian, sisipkan sehingga membentuk lingkaran (perhatikan gambar 1)

- Buatlah tusuk tunggal sebanyak 12 buah di dalam lingkaran yg sudah dibuat pada tahap 1 (perhatikan Gambar 2).

- Dari simpul pertama, ambil sisi terluar dan buat 2 tusuk ganda di setiap simpul. Lalu, teruskan sampai semua tusuk rantai terisi

- Lanjutkan putaran ke-2 sampai mencapai besar bros yang diinginkan (perhatikan Gambar 3).

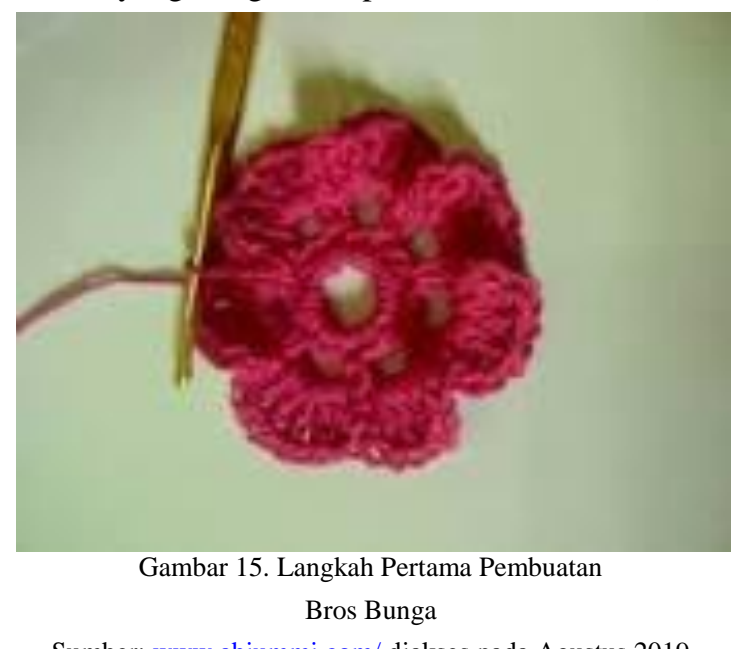

Sumber: www.abiummi.com/ diakses pada Agustus 2019

\section{B. Bagian Kedua}

Setelah langkah pertama selesai dilakukan, maka peserta pelatihan dapat melanjutkan ke bagian kedua dengan langkah sebagai berikut:

- Dari simpul pertama, ambil sisi dalam dan buatlah

3 tusuk rantai dan 2 tusuk tiga 
- Pada simpul ke-3, buatlah 3 tusuk rantai dan sl st (slip stitch atau tusuk selip atau sisip)

- Ulangi tahap 2 dan 3 sampai semua simpul terisi

- Setelah kelopak-kelopak pada rajutan bros bunga telah selesai dibuat, tempelkan kancing sebagai hiasan di atas bagian atas (bagian kedua) dengan menggunakan lem.

- Terakhir, tempelkan peniti agar dapat dijadikan bros.

\subsection{Luaran yang Dicapai}

Luaran yang dicapai pada kegiatan pengabdian ini adalah sesuai dengan sasaran obyek, yakni bagi ibuibu Komite Sekolah SDN Lowokwaru 3 Malang. Luaran yang dihasilkan adalah menghasilkan bros rajut bunga dengan tampilan sebagai berikut:

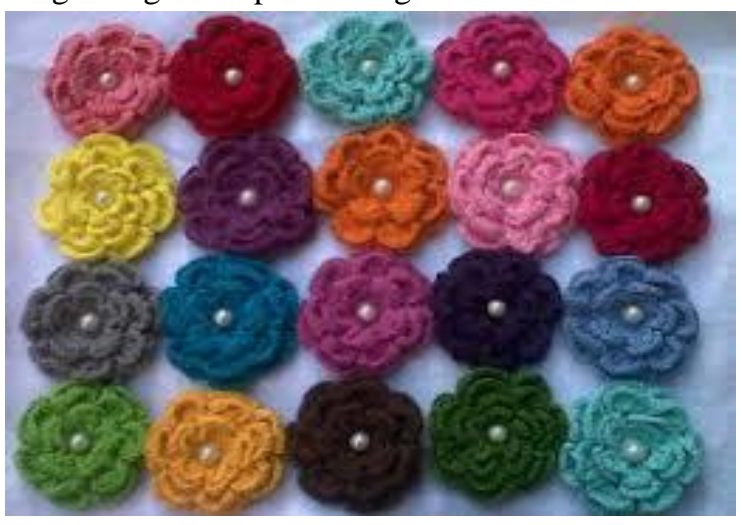

Gambar 16. Hasil Bros Rajut Bunga

Sumber: Data Diolah, 2019

- Diharapkan setelah mengerti dan melakukan kegiatan rajut dalam membuat bros bunga, maka ibu-ibu anggota komite SDN Lowokwaru 3 Malang yang tidak bekerja dan tidak memiliki penghasilan tetap dapat mencoba membuat dan memproduksi bros rajut bunga sebagai tambahan penghasilan yang bisa diandalkan.

- Selanjutnya, setelah para ibu-ibu anggota komite SDN Lowokwaru 3 Malang tersebut bisa mengaplikasikan bros rajut bunga, maka diharapkan kegiatan ini dapat direalisasikan menjadi Usaha Kecil dan Menengah yang mampu mengangkat tingkat perekonomian di dalam keluarga.

\section{KESIMPULAN DAN SARAN}

\subsection{Kesimpulan}

Kegiatan Pengabdian Kepada Masyarakat (PkM) yang telah dilaksanakan, yang berupa Bimbingan Dan Pelatihan Seni Merajut Bagi IbuIbu Anggota Komite SDN Lowokwaru 3 Malang mendapatkan antusiasme yang tinggi dengan diikuti peserta sebanyak 20 orang.

Seluruh peserta mampu mempraktekkan hasil dari bimbingan dan pelatihan tersebut, dengan menghasilkan produk berupa bros rajut berbentuk bunga yang diharapkan dapat diarahkan menjadi usaha berskala kecil dan menengah sehingga dapat menambah penghasilan ibu-ibu anggota Komite SDN Lowokwaru 3 Malang secara continue serta diharapkan kedepannya para ibu-ibu tersebut dapat menjalankan usaha sendiri dengan menjadi entrepreneur di bidang usaha rajut.

\subsection{Saran}

Saran yang dapat diberikan oleh Tim Pengabdian Kepada Masyarakat (PKM) setelah melakukan kegiatan pengabdian ini kepada Ibu-Ibu anggota Komite SDN Lowokwaru 3 Malang antara lain sebagai berikut:

- Agar para peserta dapat selalu mencoba untuk berkreasi dengan kegiatan rajut dikarenakan peluang usaha rajut sangat menjanjikan.

- Saran yang kedua adalah agar para peserta dapat selalu mencoba untuk meningkatkan jenis produksi kearah benda-benda yang sedang kekinian seperti tas rajut, dompet rajut, totbag rajut dan topi rajut. Sebuah produk tentunya harus bisa mengikuti perkembangan zaman sehingga kita sebagai pelaku usaha dapat selalu menangkap peluang pasar yang ada khususnya dalam dunia fashion bidang rajut.

- Saran yang ketiga adalah peserta harus selalu mengupgrade ilmu-ilmu yang berkaitan dengan rajut, khususnya ilmu-ilmu dalam hal pengembangan pola rajut karena produk turunan dari kegiatan rajut sangat banyak dan aplikatif.

\section{DAFTAR PUSTAKA}

[1]. Chinda, Pradya. 2018. Kreasi Crochet Unik.

[2]. Gramedia Pustaka Utama. Jakarta.

[3]. Borchers, Timothy A. 2005. Persuation in the

[4]. Media Age. New York. USA: The McGraw-Hill Companies, Inc.

[5]. Chaney, D. 2011. Life Style, Sebuah Pengantar

[6]. Komprehensif. Yogyakarta: Jalasutra

[7]. https://www.abiummi.com - diakses pada

[8]. Agustus 2019

[9]. http://www.masirul.com - diakses pada Oktober [10]. 2018 